\title{
Creating standards-based optics and photonics classes $\mathrm{K}-16$
}

\section{Neal Miller}

Neal Miller, "Creating standards-based optics and photonics classes K-16," Proc. SPIE 4588, Seventh International Conference on Education and Training in Optics and Photonics, (28 May 2002); doi: 10.1117/12.468688

SPIE Event: Education and Training in Optics and Photonics 2001, 2001, Singapore, Singapore 


\title{
Creating Standards-Based Optics and Photonics Classes K-16
}

Neal Miller, Optics \& Photonics Training Systems

\begin{abstract}
In order to get more people, especially those under-represented in the technical fields, to discover careers in lightenabling technologies, more schools must make a greater effort at an earlier age to provide qualified instruction in these areas. The hardest part of creating new curriculum is the process of establishing its credibility.

Aligning new photonics curriculum with National Science Education Standards is the most logical way to do this. Integrating optics and photonic activities that align with these established standards into the normal science curriculum allows for the measurement of student performances against these standards. This paper is about teaching strategies that use these standards to create new photonics activities and incorporate them into the K-16 classroom. It also addresses using these strategies to design classroom activities and assessments that lead to students' successful demonstration of these standards.
\end{abstract}

\section{INTRODUCTION}

\subsection{To be successful, a person must be able to:}

- Recognize a problem/set a goal

- Find and adapt information for a specific purpose

- Evaluate solutions to a problem and implement the best one

- Communicate effectively (in whatever medium is required—math, English, art)

- Collaborate with others to solve a problem/achieve a goal

- $\quad$ Produce quality work

All lesson plans need to keep these points in mind because these also become our criteria for evaluation of all processes. People who know how to do these things will be successful in any path they choose in the $21^{\text {st }}$ Century.

\subsection{Principles underlying the National Science Education Standards:}

- Science is for all students.

- Learning science is an active process.

- School science reflects the intellectual and cultural traditions that characterize the practice of contemporary science.

- Improving science education is part of a systemic education reform.

Using light as a basis for this inquiry process makes it easier to implement these standards while creating coherent, integrated curricula that produce life-long learners who can work on teams to solve problems. 


\section{METHODOLOGY}

Creating new lesson plans for a subject about which they know little is one of the harder problems facing teachers today. Developing a strategy for dealing with the perennial problem of creating lesson plans for new teachers is what prompted the creation of The Five-Question Lesson Plan. Teachers who will ask these five questions will find answers that allow them to create standards-based lesson plans.

\subsection{Standards-Based Learning}

The term "standards-based" educational programs means nothing to most people, yet teachers must have some understanding of what these standards mean if they are to provide meaningful instruction to their classes. These standards provide a meaningful framework for designing curriculum. There are six different standards:

1. Teaching Standards

2. Professional Development Standards

3. Assessment Standards

4. Content Standards

5. Program Standards

6. System Standards

Appendix A provides more detail about each of these standards. Appendix B is an outline of the Teaching Standards. Each of these standards is available in more detail on the Internet using National Science Education Standards as the search term.

Working with the content standards it becomes easier to see how light can be used. (Appendix C provides more information on science inquiry standards.) A few content standards related to light are:

- Light represents a central event or phenomenon in the natural world.

- Light represents a central scientific idea and organizing principle.

- Light has rich explanatory power.

- Light guides fruitful investigations.

- Light applies to situations and contexts common to everyday experiences.

- Light can be linked to meaningful learning experiences.

- Light is developmentally appropriate for students at the grade level specified.

The process skills are still the same when using light based concepts.

- Collect and record

- Gather data and observe

- Analyze, synthesize,evaluate, and estimate

- Analyze, synthesize, evaluate, and Infer

- Analyze, synthesize,evaluate, and develop a model

- Analyze, synthesize,evaluate, problem solve, and draw conclusions

A photonics-based science program is readily adapted to science as inquiry, physical science, life science, earth and space science, science and technology, science and personal and social perspectives, and history and nature of science curricula. Listed are some sample content standards for which these adaptations are immediately apparent.

- Properties of Matter and General Properties of Matter

- Properties of Matter, Measurement, and Atoms

- Properties of Matter, Measurement, and Molecules

- Matter, Energy, and Physical Change

- Waves, Vibrations and Light

- Waves, Vibrations, Light, and Spectrum-Color 
- Waves, Vibrations, Light, and Optics

- Waves, Vibrations, Light, and Lasers

\subsection{The Five Question Lesson Plan}

A teacher must first decide what he/she wants the outcome of the lesson to be. What should students know or be able to do when they finish the lesson? Once this is decided, the rest of the planning becomes a matter of following the steps.

1. (Objective) Decide what you want them to learn. Identification of student learning outcomes that are consistent with the National Science Education Standards

2. (Assessment) How can they show you what they have learned?

3. (Hands On Lab) What activities will get them from 1 to 2 ?

4. (Necessary Skills)What do they have to know to get to 2 ?

5. (Lesson Plan) Design the lesson to facilitate the students going from step one to step two.

Example questions:

- How can one measure things that cannot be measured directly, such as the moon, or the distance across a river?

- How can your students demonstrate that they know how do this? By measuring a designated distance with appropriate equipment?

- What activities utilize these skills? Surveying or navigating?

- What skills do they need to know in order to do this lesson? Math, measuring, graphing, trigonometry, geometry (K-12 this changes)?

- What lesson design will best allow students to move from step one to step two?

Sketch of example lesson plan:

1. How do you measure things you cannot measure directly?

2. Demonstrate how to do this with a laser.

3. Diffracted lens or astrolabe lab will allow them to do this

a. diffracted lens, metered stick lab (ratios and proportions)

b. astrolabe, sextant, transit lab (graph and $\sin / \cos$ )

4. They have to know the math for xy graphing using a protractor

a. Multiply, divide, and root functions for ratios

b. How to operate a laser safely

c. How to use a meter stick to measure distance

5. This now determines the lesson plan design.

Lab: Measuring Distance with a Laser pointer

Students set up a laser pointer utilizing standard safety precautions for a Class II laser.

Using a diffractive lens to manipulate the beam, measure the distance between the two new center beams one meter from the lens.

Now, spot the laser pointer on a distant wall with the same setup. Measure the distance between any two-center points again. Students now have enough information to utilize ratios, proportions, graphs, and sine/cosine to solve the problem. I usually start with the students graphing the results to determine the distance from the diffracted lens to the object. After a couple of graphs, ask the question: "Is there an easier way to do this?"

Can they develop other ways to do the same thing? This can be used as an Internet search activity and well as a sine/cosine math lab. 
The nice thing about math is that each of the different layers, from four function math to differential equations, was developed to solve a problem and make the new solution easier than previous methods. Once on that track, math does not become a problem but another tool the students use to solve problems.

This simple activity that can be done at levels from grades 5-16 with appropriate math, lasers and digital cameras is an example that applies to all the standards listed in the appendices. In studying different individuals who have made light and its tools possible students will discover that other factors such as relationships between science and society sometimes are more important than just the basic knowledge of how something works. Students can learn to use light to measure the circumference of this planet much as the Greeks did at the well outside Alexandria; engage in present-day computer technology and explore what light has to do with that; or take a million stops between the two. (Appendix D provides some URLs on optics and photonics lesson plans).

\section{CONCLUSION}

If different kinds of questions suggest different kinds of investigations, then it is possible for this lesson plan to incorporate any and all of the standards into its structure. After looking over the lesson plan, notice how many items in the appendices can be answered "yes." This structure allows for the flexibility teachers need and at the same time, provides a concrete guide for meeting the important science and teaching standards to make this discipline relevant in the explosion of knowledge with which students will be faced

\section{ACKNOWLEDGEMENTS}

STEP (Scientific and Technological Education in Photonics) by the University of Connecticut and CORD, funded by National Science Foundation; Grant \# DUE 9752029, Chandrasekhar Roychoudhuri, Chandra@phys.uconn.edu.

CORD (Center for Occupational Research and Development), 601 Clake Air Drive, Waco, Texas 76710.

National Science Education Standards, National Academy of Sciences, all rights reserved.

SPIE, International Society for Optical Engineering, P.O. Box 10, Bellingham, Washington 98227-0010.

OSA (Optical Society of America), 2010 Massachusetts Ave., NW, Washington, DC 20036. 
Teaching Standards for Science Teachers

\section{APPENDIX A}

Teachers of science:

A. Plan an inquiry-based science program for their students.

B. Guide and facilitate learning.

C. Engage in ongoing assessment of their teaching and of student learning.

D. Design and manage learning environments that provide students with time, space and resources for learning science.

E. Develop communities of science learners that reflect the intellectual rigor of scientific inquiry and the attitudes and social values conducive to science learning.

F. Actively participate in the ongoing planning and development of the school science program.

\section{Professional Development Standards for Science Teachers}

Professional development for teachers:

A. Requires them to learn essential science content through inquiry-based activities.

B. Requires them to integrate knowledge of science, learning, pedagogy, and students, and then apply that knowledge to the way the class is taught.

C. Requires them to create their own lifelong learning habits.

D. Requires that the programs they create be coherent and integrated.

\section{Assessment Standards for Science Education}

A. Assessments must be consistent with explicitly stated purposes.

B. Achievement and opportunity to learn science must be assessed.

C. The technical quality of data collected must be well matched to the decisions and actions taken on the basis of their interpretation.

D. Assessment practices must be fair.

E. The inferences made from assessments about student achievement and opportunity to learn must be sound.

\section{Content Standards for Science Education}

Unifying Concepts and Processes

- Systems, order, and organization

- Evidence, models, and explanation.

- Constancy, change, and measurement

- Evolution and equilibrium.

- Form and function

For each of the following Content Standards, appropriate specific applications are outlined for each age level (K-4, 5-8, 9-12) in sources such as NSTA Pathways to the Science Standards: Guidelines for Moving the Vision into Practice.

A. Science as Inquiry

B. Physical Science

C. Life Science

D. Earth and Space Science

E. Science and Technology

F. Science and Personal and Social Perspectives

G. History and Nature of Science

\section{Program Standards for Science Education}

A. All elements of the K-12 science program must be consistent with the other standards and developed within and across grade levels to meet a clearly stated set of goals created by the local teacher team.

B. The program of study in science for all students should be developmentally appropriate, interesting, relevant to students' lives, and connected with other school subjects. 
C. The science program should be coordinated with the mathematics program to enhance student use and understanding of mathematics in the study of science and to improve student understanding of mathematics.

D. The K-12 science program must give students access to appropriate and sufficient resources, including quality teachers, time, materials, and equipment, adequate and safe space, and the community.

E. All students in the K-12 science program must have equitable access to opportunities to achieve the National Science Education Standards.

F. Schools must work as communities that encourage, support, and sustain teachers as they implement an effective science program.

\section{System Standards for Science Education}

A. Policies that influence the practice of science education must be congruent with the program, teaching, professional development, assessment, and content standards while allowing for the adaptation by local teachers for local circumstances.

B. Policies that influence science education should be coordinated within and across agencies, institutions, and organizations.

C. Policies need to be sustained over sufficient time to provide the continuity necessary to bring about the changes required by the Standards.

D. Policies must be supported with resources.

E. Science education policies must be equitable.

F. All policy instruments must be reviewed for possible unintended effects on the classroom practice of science education.

G. Responsible individuals must take the opportunity afforded by the standards-based reform movement to achieve the new vision of science education portrayed in the Standards. 


\section{APPENDIX B}

\section{Teaching standards for science education}

Teaching Standard A:

Teachers of science plan an inquiry-based science program for their students. Teachers:

1. Develop a framework of year-long and short-term goals for students.

2. Select science content and adapt and design curricula to meet the interests, knowledge, understanding, abilities, and experiences of students.

3. Select teaching and assessment strategies that support the development of student understanding and nurture a community of science learners.

4. Work together as colleagues within and across disciplines and grade levels.

Teaching Standard B:

Teachers of science guide and facilitate learning. Teachers:

1. Focus and support inquiries while interacting with students.

2. Orchestrate discourse among students about scientific ideas.

3. Challenge students to accept and share responsibility for their own learning.

4. Recognize and respond to student diversity and encourage all students to participate fully in science learning.

5. Encourage and model the skills of scientific inquiry, as well as the curiosity, openness to new ideas and data, and skepticism that characterize science.

Teaching Standard C:

Teachers of science engage in ongoing assessment of their teaching and of student learning. Teachers:

1. Use multiple methods and systematically gather data about student understanding and ability.

2. Analyze assessment data to guide teaching.

3. Guide students in self-assessment.

4. Use student data, observations of teaching, and interactions with colleagues to reflect on and improve teaching practice.

5. Use student data, observations of teaching, and interactions with colleagues to report student achievement and opportunities to learn to students, teachers, parents, policy makers, and the general public.

Teaching Standard D:

Teachers of science design and manage learning environments that provide students with the time, space, and resources needed for learning science. Teachers:

1. Structure the time available so that students are able to engage in extended investigations.

2. Create a setting for student work that is flexible and supportive of science inquiry.

3. Ensure a safe working environment.

4. Make the available science tools, materials, media, and technological resources accessible to students.

5. Identify and use resources outside the school.

6. Engage students in designing the learning environment.

Teaching Standard E:

Teachers of science develop communities of science learners that reflect the intellectual rigor of scientific inquiry and the attitudes and social values conducive to science learning. Teachers:

1. Display and demand respect for the diverse ideas, skills, and experiences of all students. 
2. Enable students to have a significant voice in decisions about the content and context of their work and require students to take responsibility for the learning of all members of the community.

3. Nurture collaboration among students.

4. Structure and facilitate ongoing formal and informal discussion based on a shared understanding of rules of scientific discourse.

5. Model and emphasize the skills, attitudes, and values of scientific inquiry.

Teaching Standard F:

Teachers of science actively participate in the ongoing planning and development of the school science program.

Teachers:

1. Plan and develop the school science program.

2. Participate in decisions concerning the allocation of time and other resources to the science program.

3. Participate fully in planning and implementing professional growth and development strategies for themselves and their colleagues. 


\section{APPENDIX C}

\section{Science as Inquiry Standards}

- Understanding of scientific concepts.

- An appreciation of "how we know" what we know in science.

- Understanding of the nature of science.

- Skills necessary to become independent inquirers about the natural world.

- The dispositions to use the skills, abilities, and attitudes associated with science.

\section{Science as Inquiry Standards K-12}

Abilities necessary to do scientific inquiry

- Identify questions that can be answered through scientific investigations.

- Design and conduct a scientific investigation.

- Use appropriate tools and techniques to gather, analyze, and interpret data.

- Develop descriptions, explanations, predictions, and models using evidence.

- Think critically and logically to make the relationships between evidence and explanations.

- Recognize and analyze alternative explanations and predictions.

- Communicate scientific procedures and explanations

- Use mathematics in all aspects of scientific inquiry.

Understanding about scientific inquiry

- Different kinds of questions suggest different kinds of scientific investigations.

- Current scientific knowledge and understanding guide scientific investigations.

- Different scientific domains employ different methods, core theories, and standards to advance scientific knowledge and understanding.

- Mathematics is important in all aspects of scientific inquiry.

- Technology used to gather data enhances accuracy and allows scientists to analyze and quantify results of investigations.

- Scientific explanations emphasize evidence, have logically consistent arguments, and use scientific principles, models, and theories.

- Science advances through legitimate skepticism.

- Scientific investigations sometimes result in new ideas and phenomena for study, generate new methods or procedures for an investigation, or develop new technologies to improve the collection of data.

- All of these results can lead to new investigations.

After this the standards become more content specific for the different age groups, K-4, 5-8, and 9-12. 


\section{APPENDIX D}

\section{Lesson plan URLs}

http://www.millbury.k12.ma.us/ hs/lessonplans/ first stop how to make lesson plans using the internet http://teach1.com/tw_pages/lesson_resource_date.htm http://www.mcrel.org/products/tech/technology/techguide.asp/ another how to make lesson plans on internet http://www.goldenduck.org/lesson_plans.html/ $k$-3 http://www.physics.rutgers.edu/hex/visit/lesson/lesson_links5.html/ college physics http://www.teachnet.com/lesson/scigen.html http://chroma.mbt.washington.edu/outreach/intro.html/ examples http://arttech.about.com/hobbies/arttech/library/bl_lesson_plans_science.htm\#Lesson Plans/ more examples http://members.xoom.com/joelzahn/lightoptics/lessons.htm/ more examples of light and optics http://www.nhptv.org/kn/vs/scilab9d.htm/ NH science 7-12

http://www.unt.edu/scope/Lesson\%2520Plans/activities.htm\#Lasers/ three classic lessons jello, eye check, sound http://www.bayside.brevard.k12.fl.us/pbteacher/default.htm/ florida's version of resource page http://www.iit.edu/ smile/physinde.html http://www.ccps.org/ccps/edlinks/msteched.html/ has a bigger list than this

\section{Distance learning URLs}

\section{USA}

http://www.project2061.org/tools/ most important

http://www.project2061.org/newsinfo/earlychild/ big one with the standards

http://www.enc.org/documents/1,1341,ART-001671-index,00.shtm/ Eisenhower National Clearinghouse http://www.t-star.org/

http://www.ieee.org/organizations/eab/communications/comm-intro.htm

http://www.k12science.org/

http://www4.nationalacademies.org/cfelcfe.nsf

http://directory.netscape.com/Science/Educational_Resources

http://www.lloyd.com/k12curriculum.html

http://www.nsls.com/indexflash.html

http://www.otan.dni.us/cdlp/California's project

http://www.dlcoursefinder.com/ distance learning course finder

$\mathrm{http}: / / \mathrm{www} . e d-\mathrm{x} . \mathrm{com} /$ distance learning site

http://www.edsurf.net/ good guide to online learning

http://www.childu.com/ online for home schoolers

http://www.ecs.umass.edu/ece/wireless-center/toc.html

\section{Canada}

http://www.scn.sk.ca/

\section{Teaching and learning technology}

http://www.stjohns.edu/library/staugustine/technology.html

http://www.essdack.org/tips/ Tammy's technology tips for teachers

http://twister.coedu.usf.edu/tnt/ ideas for lesson plans

http://www.thegateway.org/ gateway to educational resources on the web

http://teams.lacoe.edu/documentation/places/lessons.html\#science/ $k$-12 lesson plans

http://mustang.coled.umn.edu/ a web66 cruising vehicle

http://trails.kcmsd.k12.mo.us/homepage.htm 